\title{
Rapid detection of ancient human mitochondrial DNA variation using tetra-primer PCR amplification
}

\author{
Yongbin Zhao ${ }^{\mathrm{a}, *}$, Changchun $\mathrm{Yu}^{\mathrm{a}}$, Hongjie $\mathrm{Li}^{\mathrm{b}}$, Ye Zhang ${ }^{\mathrm{b}}$, Hui Zhou ${ }^{\mathrm{b}}$ \\ a Jilin Provincial Key Laboratory of Plant Resources Science and Green Production, \\ Jilin Normal University, Siping, China \\ b College of Life Science, Jilin University, Changchun, China \\ *Corresponding author, e-mail: syding@jlnu.edu.cn
}

Received 12 Jun 2017

Accepted 22 Aug 2017

\begin{abstract}
Several methods have been used to diagnose the haplogroups in the maternal lineages of human remains. However, most techniques cannot be used to detect both the SNPs and the contamination. In this study, the tetra-primer PCR amplification method is used to type a number of coding-region mtDNA polymorphisms: G (4833), M9 (3394), and M10 (10 646). Results show that the tetra-primer PCR can rapidly identify mitochondrial DNA haplogroups in ancient human remains, and the result of amplification can be detected just by using agarose gel electrophoresis. Furthermore, this method can detect the existence of contamination under certain conditions.
\end{abstract}

KEYWORDS: ancient DNA, tetra-primer polymerase chain reaction

\section{INTRODUCTION}

Since the genetic examination of the Quagga and an ancient Egyptian mummy, ancient DNA (aDNA) has attracted the interest of more and more academics, such as geneticists, historians, and archaeologists $^{1}$. Unlike modern DNA, aDNA analysis can involve direct analysis of ancient organism remains from specific time periods. Thus it is a powerful method to uncover the development processes of populations. Nowadays, whole genome sequencing is widely used in analysis of aDNA ${ }^{2}$, and mitochondrial DNA (mtDNA) is still a frequently adopted marker in many studies ${ }^{3}$ because it has many more copies within each sample compared to nuclear DNA, increasing the opportunity for DNA extraction. In traditional methods of mtDNA analysis, besides amplifying the mtDNA hypervariable region I (HVR I), some coding region single-nucleotide polymorphisms (SNPs) have been identified to assign the mitochondrial DNA haplogroup. Many techniques, such as restriction fragment length polymorphism ${ }^{4}$, amplified product-length polymorphisms ${ }^{5}$, direct sequencing, and snapshot primer extension technique $^{6}$ have been used in a wide range of human populations to define the haplogroups. However, these techniques are still onerous or expensive. Owing to minute amounts and the degraded nature of surviving DNA, aDNA is prone to extraneous DNA contamination ${ }^{7}$. Unfortunately, none of the techniques mentioned above can be used to detect directly both the SNPs and the contamination. Recently, high-throughput sequencing technology has been applied to aDNA research. However, this technique is still too expensive for many small laboratories, although it can better solve this problem.

As early as 1992, an effective SNP typing approach, tetra-primer PCR amplification, was developed $^{8}$. According to that technique, four primers, two longer flanking primers and two shorter internal primers, were used in PCR reaction in conjunction with two temperature programs. A different length DNA fragment was obtained according to different allele, which could be distinguished by agarose gel electrophoresis, and both fragments were yielded from heterozygous mutation ${ }^{8}$. In this study, we design a variant PCR reaction based on the tetra-primer PCR amplification. This method also needs four primers, and amplification results can be detected by using agarose gel electrophoresis. The difference is that the annealing temperatures of these primers are almost equal, and only one temperature program is used in PCR amplification. In this reaction system, there are two consensus primers which will yield the larger fragment. There are two specific primers according to the different allele. One of them is completely complementary to the sense strand of DNA and the other is to the antisense strand of DNA, the $3^{\prime}$ end of them locates the same SNP site but is different according to different allele. In a PCR amplification reaction using this method, three of four primers are available. Thus 
Table 1 Primers used in this study.

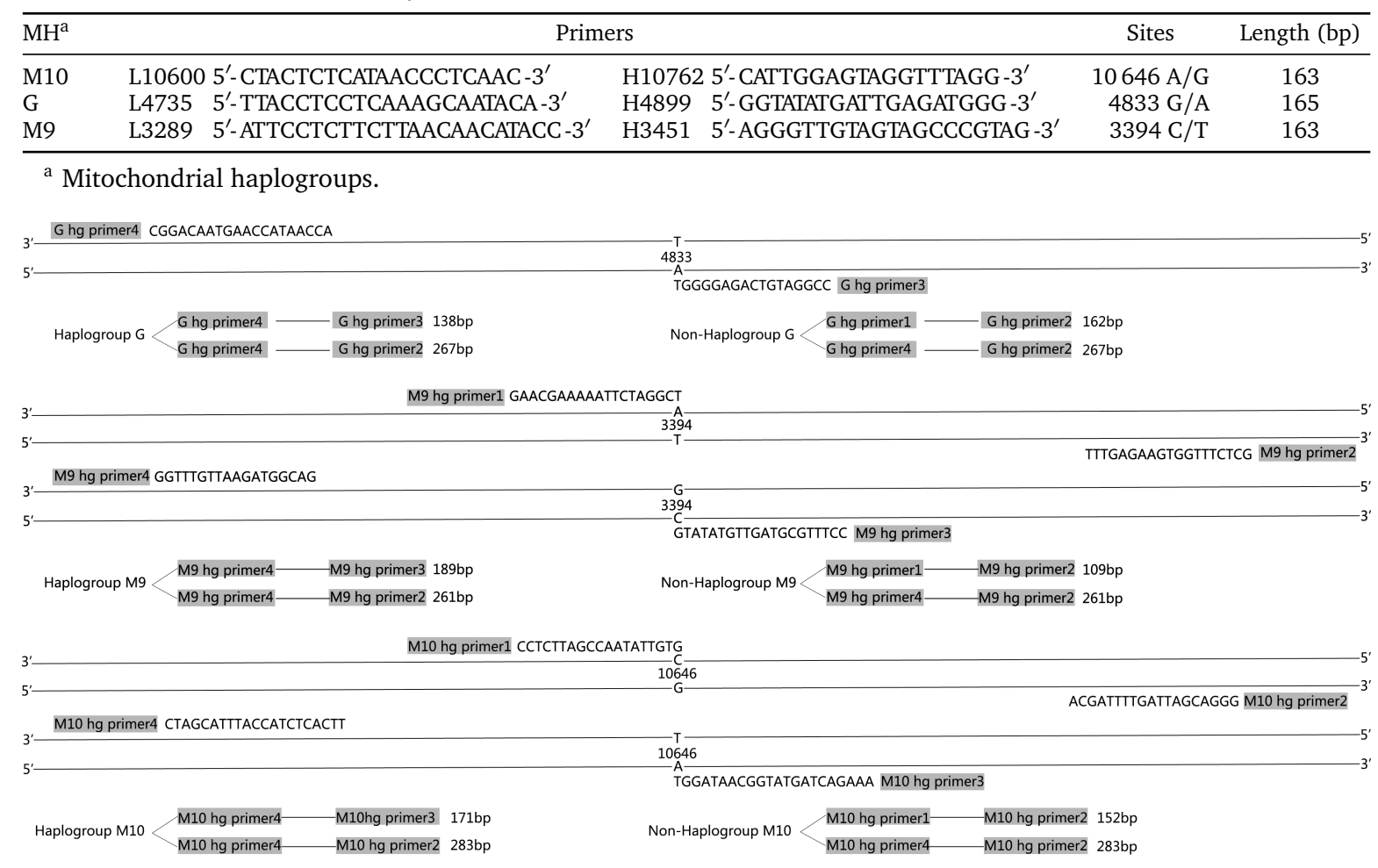

Fig. 1 Design of the oligonucleotide primers.

two DNA fragments could be obtained. The larger fragment containing SNP point was equal in both haplotypes, and the smaller one could determine SNP type according to its length. Because of the extensive damage of aDNA, very low efficiency or failure often occurs in the amplification of a large aDNA fragment ${ }^{7}$. Thus we can detect the contamination of modern DNA according to whether the larger one was obtained, and detect the SNP to identify the haplogroup according to the length of the smaller one. Again, because only one smaller fragment is obtained in a PCR amplification, we also detect the cross-contamination among samples according to whether the larger fragment was obtained or not. Here, we used the variant tetraprimer PCR amplification method to type a number of coding-region mtDNA polymorphisms-G (4833), M9 (3394), and M10 (10646) ${ }^{9}$. We choose the samples attributed to these three haplogroups. This can help us to better detect the existence of potential contamination from modern DNA.

\section{MATERIALS AND METHODS}

Eleven samples from human remains were excavated from three sites: nine samples from Hengbei site $^{10}$, one sample from Taojiazhai site ${ }^{11}$, and one from Pengyang site ${ }^{12}$. DNA of one researcher in our laboratory, who was attributed to haplogroup B, was also analysed as a positive control. These samples were analysed by a mitochondrial DNA marker from the previous study. The haplogroup $(\mathrm{Hg}) \mathrm{M} 9$ and $G$ of the ancient samples were diagnosed by APLP and the $\mathrm{Hg} \mathrm{M} 10$ was typed by sequencing. The $\mathrm{Hg} \mathrm{B}$ of the positive control sample was identified using electrophoresis to detect the presence of a CoII/tRNAlys 9-bp deletion ${ }^{10-12}$. To test the authenticity of the results of this study, a DNA fragment including the mutations at positions $4833(\mathrm{Hg} \mathrm{G})$, 3394(Hg M9), and 10 646(Hg M10) was amplified and sequenced. The primers used in this study are listed in Table 1 . The design of the oligonucleotide primers was based on the key coding region SNPs of each haplogroup according to the well-defined mtDNA phylogenetic tree ${ }^{13}$ (Fig. 1).

All analyses were conducted in the professional ancient DNA laboratory, following the criteria for ancient DNA studies previously published. The protocols used in this study, such as ensuring authenticity, ancient DNA extraction and polymerase chain reaction, have been previously published ${ }^{14}$. Modern genomic DNA was extracted from Oral mucosa cells using Chelex-100 resin. The quality of 
Table 2 Sampling information.

\begin{tabular}{llclcl}
\hline Site & Sample & DNA content $(\mathrm{ng} / \mu \mathrm{l})$ & HVR-I mutations $(16000+)^{\mathrm{a}}$ & Coding region SNPs & Hg \\
\hline PY & XT19 & 2.16 & 223,311 & $10646(\mathrm{~A})$ & M10 \\
TJZ & PW7 & 13.60 & $093,129,193,223,311357$ & $10646(\mathrm{~A})$ & M10 \\
HB & M1009i & 0.31 & 223,362 & $4833(\mathrm{G})$ & $\mathrm{G}$ \\
& M2044 & 0.41 & $223,234,248,265 \mathrm{~T}, 316,362$ & $3394(\mathrm{C})$ & M9 \\
& M2045 & 0.42 & $66,223,248,265$ T, 316, 362 & $3394(\mathrm{C})$ & M9 \\
& M2083 & 0.55 & 223,265 T, 316, 362 & $3394(\mathrm{C})$ & M9 \\
M2149 & 0.44 & 223,265 T, 316, 362 & $3394(\mathrm{C})$ & M9 \\
M3374 & 0.33 & $223,291,316,362$ & $3394(\mathrm{C})$ & M9 \\
M2021 & 0.50 & 223,311 & $10646(A)$ & M10 \\
M2158ii & 0.62 & 223,311 & $10646(A)$ & M10 \\
M2144ii & 0.42 & $66,223,311$ & $10646(A)$ & M10 \\
R & 25 & $189,261,278,311,362$ & $9-b p$ deletion CoII/tRNAlys & B \\
\hline
\end{tabular}

a The data have been published in the previous studies ${ }^{10-12}$.

amplification was estimated on a 3\% agarose gel. The DNA concentration of samples was detected using NanoDrop One (Thermo Scientific, USA).

\section{RESULTS}

The potential for exogenous DNA contamination was minimized by strict precautionary procedures. All the samples selected in this study were successfully amplified because they were analysed successfully in previous studies ${ }^{10-12}$. In the whole process of this study, no amplification products were obtained from negative controls. The electrophoretograms of all samples were consistent with their haplogroups identified in previous studies and this study (Table 2). Considering that none of the researchers in our laboratory is attributed to haplogroup G, M9, or M10, we deduced that the obtained amplification fragments were not artefacts or the result of contamination.

In tetra-primer PCR amplification, the nucleotide substitutions were detected as amplified fragments with different lengths ${ }^{8}$. The differences in amplified fragment length between one haplogroup and another haplogroup were detected to be more than 19 bp (Fig. 1) by agarose gel electrophoresis. Each haplogroup was clearly and unambiguously distinguished by the band patterns (Fig. 2). In this study, Samples M2021, M2158ii, and M2144ii yielded only a small fragment of $171 \mathrm{bp}$ and were attributed to Hg M10. However, both PW7 and XT19 yielded not only the small fragment but also a large fragment of $283 \mathrm{bp}$. Five samples, M2044, M2045, M2083, M2149, and M3374 produced a small fragment of 189 bp and were identified as Hg M9. M1009i attributed to haplogroup $\mathrm{G}$ also only yielded a small fragment of

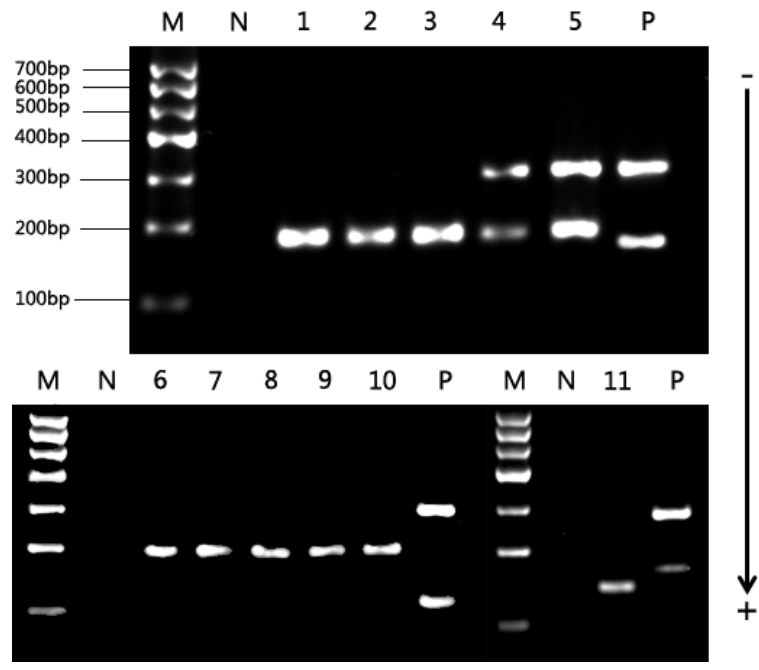

Fig. 2 Banding patterns of tetra-primer PCR on a $3 \%$ agarose gel. Lane M, DNA marker I; Lane N, negative control; Lane P, positive control (modern sample R); Lane 1, M2021; Lane 2, M2144ii; Lane 3, M2158ii; Lane 4, PW7; Lane 5, XT9; Lane 6, M2044; Lane 7, M2045; Lane 8, M2083; Lane 9, M2149; Lane 10, M3374; Lane 11, M1009i.

$138 \mathrm{bp}$.

\section{DISCUSSION}

As mentioned above, tetra-primer PCR can yield one large fragment and one short fragment in theory. However, ancient DNA is always partially degraded and chemically modified. Ancient DNA molecules are often fragmented into very short pieces, and the mean ancient DNA fragment length varied from $60-150 \mathrm{bp}^{15}$. Generally, there is an inverse correlation between the size of the PCR amplicons 
and the amplification efficiency for ancient DNA ${ }^{15}$. It means that the large fragment DNA, compared with the small one, is more difficult to amplify. In theory, if the preservation of the DNA is worse, the amplification of large fragment DNA will fail. In contrast, a good preservation of the DNA can result in the successful amplification of both large and small fragment DNA.

In this study, as $\mathrm{R}$ was a modern sample, in which DNA damage and degradation seldom occurred and DNA concentration reached $25 \mathrm{ng} / \mu \mathrm{l}$ (Table 2), it could be expected that $\mathrm{R}$ would yield a large fragment (Lane P in Fig. 2). Samples PW7 and XT19 were from Pengyang site ( $\sim 2500$ years old) and Taojiazhai site ( $\sim 1500$ years old), respectively. Thanks to the cold and dry environmental conditions and that the samples were freshly excavated, the DNA of these samples was in good condition. Their concentration reached 13.60 and $2.16 \mathrm{ng} / \mu \mathrm{l}$ (Table 2), respectively. Most of the samples from these two sites had been successfully amplified in previous studies. The success rate of DNA amplification from Pengyang site samples was $100 \%{ }^{12}$, and that of Taojiazhai site samples was $94 \%{ }^{11}$. Thus the amplification of DNA from PW7 and XT7 could yield both small fragments and large fragments, although the large one was $283 \mathrm{bp}$. In contrast, because the Hengbei site dates back to approximately 3000 years ago, the preservation of the DNA from this site was poorer than that of Taojiazhai and Pengyang. All nine samples from Hengbei site contained DNA below $1.0 \mathrm{ng} / \mu \mathrm{l}$. Furthermore, the success rate of DNA amplification of Hengbei site samples was $72 \%$ in a previous study ${ }^{10}$. Thus the samples could only yield small fragments. The variant tetra-primer PCR could rapidly identify ancient human mitochondrial DNA haplogroups, and the result of amplification could be detected only using agarose gel electrophoresis. In theory, this method can also directly detect extraneous DNA contamination. However, it might be generally affected by the preservation state of samples. The detection of the content of ancient DNA is necessary before the process of haplogroup diagnosis using tetra-primer PCR amplification is conducted. The utmost attention should be paid to extraneous DNA contamination if a large fragment was obtained and the sample amplified showed a poor preservation state.

Acknowledgements: This study was supported by the National Science Fund of China (Grant No. 31200936). We thank Prof. Yingduo Ji for assistance with revision of the paper.

\section{REFERENCES}

1. Hofreiter M, Serre D, Poinar HN, Kuch M, Pääbo S (2001) Ancient DNA. Nat Rev Genet 2, 353-9.

2. Rasmussen M, Li Y, Lindgreen S, Pedersen JS, Albrechtsen A, Moltke I, Metspalu M, Metspalu E, et al (2010) Ancient human genome sequence of an extinct Palaeo-Eskimo. Nature 463, 757-62.

3. Fu Q, Meyer M, Gao X, Stenzel U, Burbano HA, Kelso J, Pääbo S (2013) DNA analysis of an early modern human from Tianyuan Cave, China. Proc Natl Acad Sci USA 110, 2223-7.

4. Wallace DC, Brown MD, Lott MT (1999) Mitochondrial DNA variation in human evolution and disease. Gene 238, 211-30.

5. Umetsu K, Tanaka M, Yuasa I, Saitou N, Takeyasu I, Fuku N, Naito E, Ago K, et al (2001) Multiplex amplified product-length polymorphism analysis for rapid detection of human mitochondrial DNA variations. Electrophoresis 22, 3533-8.

6. Brandstätter A, Parsons TJ, Parson W (2003) Rapid screening of mtDNA coding region SNPs for the identification of west European Caucasian haplogroups. Int J Leg Med 117, 291-8.

7. Cooper A, Poinar HN (2000) Ancient DNA: do it right or not at all. Science 289, 1139.

8. Ye S, Humphries S, Green F (1992) Allele specific amplification by tetra-primer PCR. Nucleic Acids Res 20, 1152 .

9. Wen B, Li H, Lu D, Song X, Zhang F, He Y, Li F, Gao Y, et al (2004) Genetic evidence supports demic diffusion of Han culture. Nature 431, 302-5.

10. Zhao YB, Zhang Y, Zhang QC, Li HJ, Cui YQ, Xu Z, Jin L, Zhou H, et al (2015) Ancient DNA reveals that the genetic structure of the northern Han Chinese was shaped prior to 3,000 years ago. PLoS ONE 10, e0125676.

11. Zhao YB, Li HJ, Li SN, Yu CC, Gao SZ, Xu Z, Jin L, Zhu $\mathrm{H}$, et al (2011) Ancient DNA evidence supports the contribution of Di-Qiang people to the han Chinese gene pool. Am J Phys Anthropol 144, 258-68.

12. Zhao YB, Li HJ, Cai DW, Li CX, Zhang QC, Zhu H, Zhou H (2010) Ancient DNA from nomads in 2500year-old archeological sites of Pengyang, China. J Hum Genet 55, 215-8.

13. Yao YG, Kong QP, Bandelt HJ, Kivisild T, Zhang YP (2002) Phylogeographic differentiation of mitochondrial DNA in Han Chinese. Am J Hum Genet 70, 635-51.

14. Li CX, Li HJ, Cui YQ, Xie CZ, Cai DW, Li W, Mair VH, $\mathrm{Xu} Z$ Z, et al (2010) Evidence that a West-East admixed population lived in the Tarim Basin as early as the early Bronze Age. BMC Biol 8, 15.

15. Prüfer K, Stenzel U, Hofreiter M, Pääbo S, Kelso J, Green RE (2010) Computational challenges in the analysis of ancient DNA. Genome Biol 11, R47. 